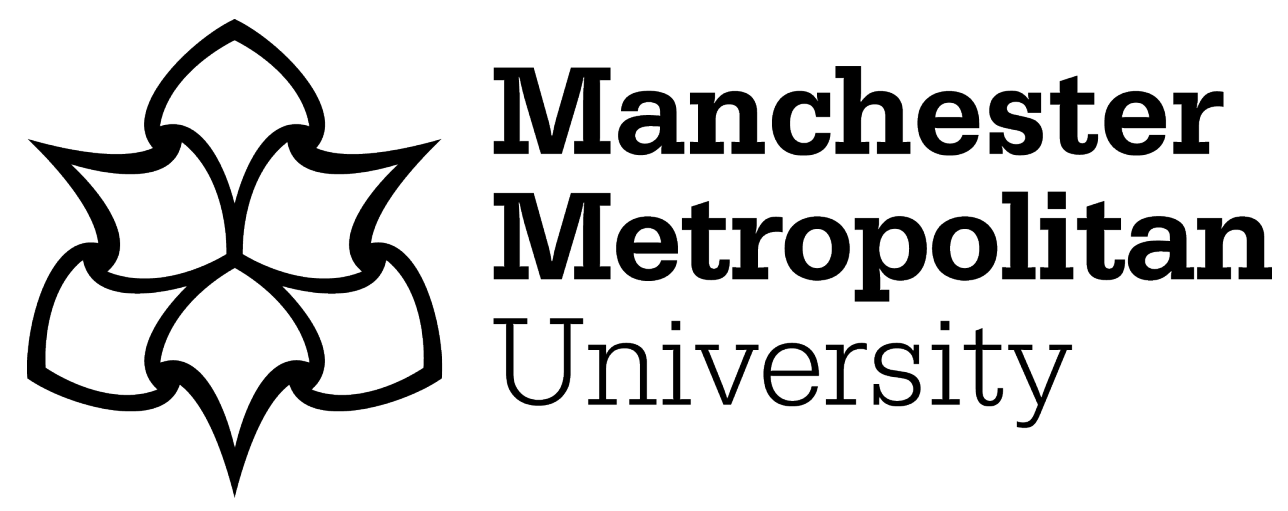

de Freitas, E (2017) The biosocial subject: sensor technologies and worldly sensibility. Discourse: studies in the cultural politics of education, 39 (2). pp. 292-308. ISSN 0159-6306

Downloaded from: https://e-space.mmu.ac.uk/620737/

Version: Accepted Version

Publisher: Taylor \& Francis

DOI: https://doi.org/10.1080/01596306.2018.1404199

Please cite the published version 
de Freitas, E. (2018). The biosocial subject: Sensor technology and worldly sensibility.

Discourse: Studies in the Cultural Politics of Education, 39 (2), 292-308.

\title{
The biosocial subject: Sensor technologies and worldly sensibility
}

\section{Elizabeth de Freitas*}

\author{
Education and Social Research Institute, Manchester Metropolitan University
}

\begin{abstract}
Sensor technologies are increasingly part of everyday life, embedded in buildings (movement, sound, temperature) and worn on persons (heart rate, electro-dermal activity, eye tracking). This paper presents a theoretical framework for research on computational sensor data. My approach moves away from theories of agent-centered perceptual synthesis (on behalf of a perceiving organism) and towards a more expansive understanding of the biosocial learning environment. The focus is on sensor technologies that track sensation below the bandwidth of human consciousness. I argue that there is an urgent need to reclaim this kind of biodata as part of an unequally distributed worldly sensibility, and to thereby undermine more narrow reductive readings of such data. The paper explores the biopolitical implications of recasting biodata in terms of transindividual inhuman forces, while continuing to track the distinctive power of humans.
\end{abstract}

Keywords: biosocial; sensor technology; electro-dermal; posthumanism; environmental sensibility; worlding

\section{Introduction}

Biosocial research is at the vanguard of a radical reconfiguring of education research, merging research methodologies from the life sciences and the social sciences (Youdell, 2016). Such research is increasingly being advocated at national policy levels, responding to scientific developments and paradigm shifts in various disciplines. ${ }^{1}$ Many contemporary biosocial interventions, however, are being harnessed to highly conventional and reductionist models of learning, conceived in terms of faster or more effective transit through pre-defined stages. Biotechnologies and 'biopedagogies' are being used with children and adults to track and modify attention, engagement, decisionmaking, emotional states, motion, performance and creativity (Williamson, 2016). The sensor technologies that are central to this kind of research carry serious ethical implications as they permit new levels of intervention into the bodies, mental states and conduct of individuals and groups (Nafus, 2016). Moreover, behaviour interventions are typically grounded in normative assumptions based on control or correction of bodily phenomena that irritate dominant notions of proper conduct (e.g. 'fidgeting', repetitive

\footnotetext{
*Corresponding author's email: L.de-Freitas@mmu.ac.uk
} 
de Freitas, E. (2018). The biosocial subject: Sensor technology and worldly sensibility. Discourse: Studies in the Cultural Politics of Education, 39 (2), 292-308.

gestures, noises, agitation, or the turbulence of crowds). Deployments of biotechnologies to track such behavior are easily, and often rightly, critiqued on ethical and pedagogical grounds (Gillborn, 2016).

It is also important, however, to move beyond the agonistics of critique and towards creative experimentation and the development of new theory. The shift to the biosocial is exciting for many reasons, not least in that it allows us to attend to capacities that are often overlooked or poorly understood in conventional educational and social research (Goodman, 2013; Meloni, Williams, \& Martin, 2016). There are important variants of biosocial research that could support such explorations, using the concepts of emergence, thresholds, affective intensities and creative experimentation, attending to the aesthetic dimensions of learning environments, and tracing affects and sensations that conventional research methods fail to encounter. Rose (2013), for instance, pursues -

an 'affirmative relationship' with an emerging 'new and non-reductive biology of human beings and other organisms in their milieu ... which can thus be brought into conversation with ... the social and human sciences. (p. 24)

This paper focuses on how biosocial research might generate new forms of experimentation that take up scientific knowledge beyond the procedures of normative science. This aim resonates with other biosocial projects informed by new materialisms (Fitzgerald \& Callard, 2015; Frost, 2016), feminist science and technology studies (Wilson, 2015), and attempts to study nature-culture mixtures (Ingold \& Palsson, 2013; Kohn, 2013). I follow Wilson (2015) who argues that social theory should become more biochemically literate, to reconsider the relational force of pharmaceuticals, metabolism, and the capacity of 'biological substances'. On the other hand, I am sensitive to the fact that ebullient affirmations of the force of the bio-chemical without adequate critique, as sometimes found in current work on affect, need to be interrogated (Papoulias \& Callard, 2010). And interdisciplinary projects across the social and biological sciences are often sites where 'the biosocial nexus starts to look distinctly bio-centric' (Fitzgerald \& Callard, 2015, p. 14).

The primary contribution of this article will be in the area of conceptual development around this paradigm shift, with particular focus on how new biotechnology might be used to study a more-than-human worldly sensibility. Specifically, the main aim of this article is to show how biosensor data might serve in further developing posthuman theories of learning. The term sensor technology is used to reference all technologies that produce sensory data about the body or the environment (movement, temperature, air quality, arousal, light, etc.). ${ }^{2}$ While avoiding techno-fantasies, either utopian or dystopic, the aim is to trigger imaginings about the potential use of biotechnologies in education research. I offer an argument as to why social science researchers might reclaim and repurpose these digital plug-ins, subverting the interests of the control state by showing how such data actually points to the profoundly relational and materially distributed nature of learning. I hope this work contributes to the ongoing process of formulating a robust bioethics adequate to twenty-first century new empiricisms, by reclaiming biodata that all too often is used to pathologize the individual human body. I argue instead that digital microsensors produce evidence of a more-than-human worldly sensibility. This theoretical reframing of biodata is an important step in addressing some of the political concerns associated with the 'biosocial subject' (Colebrook, 2014; Protevi, 2013). 
de Freitas, E. (2018). The biosocial subject: Sensor technology and worldly sensibility. Discourse: Studies in the Cultural Politics of Education, 39 (2), 292-308.

Biosocial research must be considered part of a current transformation of biology itself, as it becomes increasingly computational and data driven (Stevens, 2013). Biotechnologies are today more seamlessly integrated into organic processes; and machine learning algorithms are increasingly used in concert with such hardware, suggesting that the near future will hold a convergence of the biological, the digital, the sensual, and the social (Platoni, 2015). Freeman Dyson (2007) declares the 'domestication of biotechnology' in transforming our lives in the next 50 years, predicting that biology will be to the twenty-first century what physics was to the twentieth. This new Biology 3.0 will operate without the biological/digital divide, merging 'wet' and 'informatic' perspectives into one all encompassing biosocial paradigm. This transformation in the bio-digital-social mixture entails new ways of doing research in the social sciences (de Freitas, 2016a, 2016b; Ruppert, Law, \& Savage, 2013) and new ways of understanding our 'quantified selves' (Lupton, 2014). In pursuing this project, we hasten to remind readers that the term 'biosocial' retains problematic associations with past Eugenics movements, and recalls previous misuses of biological sciences (Gravlee, 2009; Meloni et al., 2016). We must keep these historical links in mind as we consider a possible rapprochement between biology and the social sciences.

To that end, my aim is to develop a particular approach to biosocial research that shows how digital bio-data belongs to learning environments rather than to individuated organic bodies. This paper focuses on biosensors that are commonly used to tap the human body for physiological biodata. Wearable sensor technology is now a common way of collecting data from the human body, using new digital microsensors worn on the skin (Coenen, Coorevits, \& Lievens, 2015). Here we focus on electrodermal bracelets which are said to offer clinical quality observation and monitoring of temperature, movement, blood-volume pulse, and electro-dermal activity (Banaee, Ahmed, \& Loutfi, 2013). I discuss in particular one such bracelet produced by Empatica, a company that focuses on 'affective computing and data analytics'. Empatica designs and sells wearable digital devices for 'clinical quality sensing' serving hospitals and research organizations such as MIT, INTEL, SONY, MICROSOFT, and various universities, wherever there is interest in biometric data.

I work with ideas from Elizabeth Wilson (2015), John Protevi (2013), and Mark Hansen (2015) to argue that such technical intrusions produce evidence of an impersonal worldly sensibility infusing and sustaining an ecology of material practices. This approach recasts biosocial research as the ecological study of complex dynamic systems and 'atmospheric media' (Hansen, 2015). I argue that electro-dermal digital data belong to the charged learning environment, and that we must find ways of framing that data in terms of the dynamic fluctuations and entanglements of that environment. This approach troubles the very idea of the organism as the unit of inquiry, and thus differs from related epigenetic research, which continues to focus on the organism insofar as it 'responds to the environment' through epigenetic regulation of gene expression. In so doing, I hope to trouble some of the assumptions of post-cybernetic organicism found in current epigenetic research which treats 'the social as signal' and continues to operate within a single causal arrow, albeit granting significant force to the environment. ${ }^{3}$ Rather than claim that the environment becomes embodied in the 'epigenome' (van Ijzendoorn et al., 2011, p. 309), and rather than focus on trauma and pathology (like most epigenetic research (Meloni, 2016), I read biodata as part of the radical exteriority of experience, and 
de Freitas, E. (2018). The biosocial subject: Sensor technology and worldly sensibility. Discourse: Studies in the Cultural Politics of Education, 39 (2), 292-308.

as evidence of the inhuman forces at play in any environment. This approach takes up the notion of signal quite differently, drawing on the work of the media theorist Mark Hansen, who studies the inherent technicity of matter and life, emphasizing how digital media sense and actuate below the time-scale of the human.

Hansen (2015) argues that digital biosensors plug into a worldly sensibility, and suggests that these new digital intrusions are able to access 'primordial sensibility' ( $\mathrm{p}$. 222) and 'enjoy a sensory domain all their own' (p. 234). New mobile media (ubiquitous computing) can be studied less as Cyborgian extensions of human faculties, and more as registering the 'environmentality' of the world (p. 8). On the one hand, digital media produce data that is about sensibility (i.e. a sensor records electro-dermal activity on the skin), while on the other hand, this data is sensibility (i.e. a sensor plugs into worldly sensation). Thus meaning ('about') and being ('is') are digitally coupled in ways that make our particular historical moment distinctive. In other words, the digital nature of our current data deluge makes for a singular synchronicity of being and meaning. And to the extent that digital sensors are not mimicking or magnifying human perceptual organs, but instead expanding the distribution of more-than-human sensation, this seems a valid point. Moreover, this seems to entail a 'media-driven transformation of human experience itself' and thus a move from an 'agent-centered perceptual modality to an environmental sensibility' (p. 8). This paper explores the ways in which sensor data at micro-scales forces us to imagine life quite differently, and to seek the inorganic potentialities and inhuman forces by which a body can 'branch out into territories beyond its own selfmaintenance' (Colebrook, 2011, p. 26).

\section{Microsensors: data-mining the electric body}

The Empatica E4 wristband is designed to record continous 'real time' data during waking or sleeping hours. It contains a 3-axis accelerometer that tracks motion, an infrared thermopile to track temperature, a photoplethysmography sensor (PPG) that measures blood volume pulse (BVP), from which heart rate, heart rate variability (HRV), and other cardiovascular features may be derived. It also contains an electro-dermal activity sensor (EDA) 'used to measure sympathetic nervous system arousal and to derive features related to stress, engagement, and excitement'. Central to my argument is the fact that these bio-sensors are not operating prosthetically, because they engage with the body in a more distributed and unconscious way, and thus have no correlate to the usual embodied organs, but instead seem to transcend the very notion of organism, while still, paradoxically, mobilizing embodied forces.

The Affective Computing Lab at MIT uses these bracelets in a multitude of projects to study 'skin conductance' associated with stressful activity, tracking the variability in how people express stress physiologically. Most of the projects are entirely focused on how such data belongs to an individual human body, and how such data is the expression of affect possessed by that individual human body. In addition, projects affiliated with the lab that are focused on learning assume that such data underscores the cognitive achievements of that individual body. One such project studies children as they play with LEGO blocks (http://affect.media.mit.edu/). Researchers claimed that wrist EDA sensors showed that 'children are excited to take on new responsibilities but are then quickly 
de Freitas, E. (2018). The biosocial subject: Sensor technology and worldly sensibility. Discourse: Studies in the Cultural Politics of Education, 39 (2), 292-308.

discouraged when they aren't given the resources to succeed'. They also claimed that children didn't always recognize their own achievements, based on the EDA data. In other words, the research suggests that skin conductance is a better or more accurate way of determining when children have accomplished something, rather than facial expression or verbal or other visible activity, and that there is a disconnect between these kinds of data, revealing that children do not know when to value what they have done.

The aim of the Lego project is uncritically industry-oriented, as the researchers claim that 'by using skin conductance sensors, we can help companies better understand the unique perspective of children and build experiences fit for them'. This research is thus explicitly invested in using the EDA data to serve corporate interests, as they redesign and 'personalize' learning experiences that maximize the individual child's affective engagement, as well as their accurate evaluation of their embodied actions. These aims together reveal how so much of the EDA research inspired by and emerging from the MIT Affective Computing Group is based on a desire to correlate and also control the degree of intensity in any learning experience, and to cultivate self-regulation of affect in children. ${ }^{4}$

At MPath, a company that pursues 'Empathic design through rigorous science', EDA data is used to show when people are un/excited, dis/engaged, or stressed. In learning experiments, the data is typically used to show when affect interferes with or supports a goal of some kind. MPath interprets fluctuation in skin conductance as evidence of stress, when for instance the EDA graph shows a series of hills and troughs during the experiment. They interpret large singular spikes in EDA data as excitement or severe anxiety, and a trailing off of EDA levels as a sign of disengagement. In the figure below, EDA data from a child is shown, while he uses some building blocks with his mother. The EDA data is said to correlate with two possible scenarios, the first tracking positive excitement, the second negative anxiety. These two interpretations underscore the inherent ambivalence of this data: (1) the falling graph marks the boredom of a child as he watches his mother build a block toy, followed by the positive excitement and fluctuation of the EDA when the child works independently. An alternative interpretation of the same data might be (2) the calmness of the child while he watches his mother build a block toy, followed by the negative stress and fluctuation of the EDA when he anxiously builds independently. The data does not definitively indicate one or the other, although the researchers state that the boy Mason 'slouches' and begins chatting about the blocks, losing interest in what his mother is doing during the first minute.

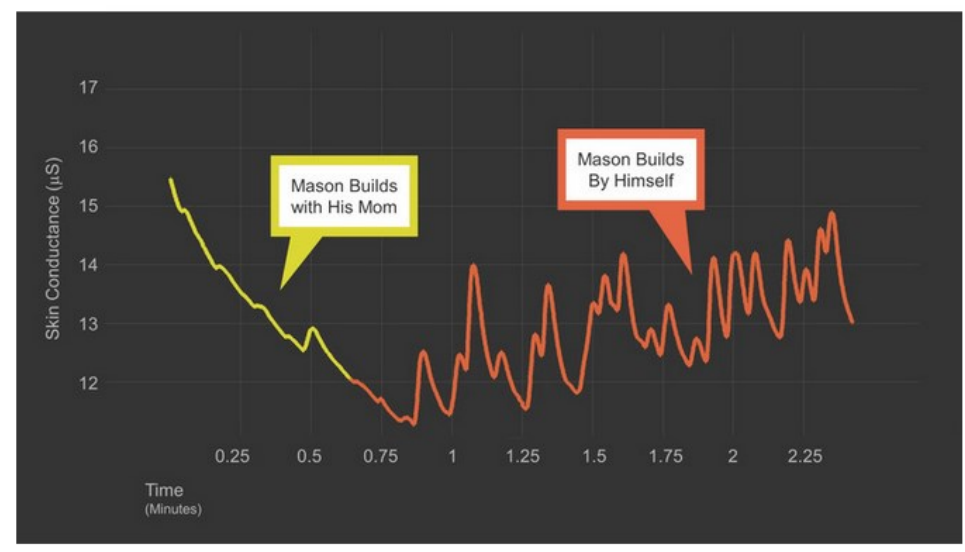


de Freitas, E. (2018). The biosocial subject: Sensor technology and worldly sensibility. Discourse: Studies in the Cultural Politics of Education, 39 (2), 292-308.

Figure 1: Source (http://www.buildempathy.com/emototype/).

The main textbook on EDA research was written in 1992 by Boucsein, with a second edition released in 2012. EDA is part of a larger set of data - electrodermal biosignals which are now the most commonly used data in psychophysiology. Despite the widespread use of such data, electrodermal phenomena are not fully understood. EDA refers to all possible electrical dermal data, including PET and fMRI scans, and thus is at the heart of neuroscience as well as other physiological work today. Electro-dermal experiments with humans and animals have a long and checkered history, including horrific public displays of the power of electricity to shock animals into submission (or death), and discredited liar detection devices and other experimental instruments said to correlate electric current with social disposition or competency. Bertucci \& Pancaldi (2001) recount episodes in the history of medical electricity, tracking scientific interest in the 'electric body' over many centuries. Luigi Galvani's theory of animal electricity, published in 1792, De viribus electricitatis in motu musculari, triggered a new line of investigation into electrophysiology (Piccolini \& Bresadola, 2013). Even before its publication, in the mid-eighteenth century, when natural philosophy and medical electricity were forging new kinds of empiricism, electric shocks were administered, using Leydon jars, to 'penetrate' the patient's body with whatever medical substance was mixed with the water in the jar. I mention this work so as to situate any current developments within this ongoing interest in the electric body.

With this checkered history in mind, I attempt to reconsider potential uses of the new electro-dermal technologies that tap the electric body without violent intervention, in this case 'passively' collecting data about the electro-physiology of the body. My argument, however, is not that the EDA data is evidence of an emotion or affect possessed by the human organism, but that skin conductance can be studied as evidence of the radical exteriority of experience, and as evidence of the transitive, relational event-nature of learning. Sensor data is profoundly indeterminate and thereby refuses to belong to any one organism, overturning conventional notions of 'learning' from an agent-centered perceptual modality to an unequally distributed 'environmental sensibility' (Hansen, 2015). This perspective underscores the need to rethink embodiment, and the need to introduce 'a more porous and less self-referential conception of embodiment, a conception that understands the body to be a society of microsensibilities themselves directly and atomically susceptible to technical capture' (Hansen, 2015, p. 193).

What follows is an attempt to reclaim this data as environmental. I am interested in the way that EDA data points to alliances that are formed between 'internal' organic processes and more distributed processes. I submit that affects, nerves, cells, skins, buildings and sociality intra-act in just the way that speculative Biology 3.0 might suggest. Rather than dismiss EDA data as irrelevant or insignificant, or serving only to individualize and pathologize the learner, I want to trouble the all too easy antibiologisms of social theory, and explore the entanglements of biochemistry, ecology, and learning. My focus on skin conductance is a way of attending to the neurological periphery - the far flung electrical activity of the body - rather than what is assumed to be the center and administrator of that system, the brain. I am less interested in the central nervous system (the brain, the spinal cord), than in the 'distributed network of nerves that innervates the periphery' (Wilson, 2015, p. 5). The electrical charge that innervates the skin is at the 
de Freitas, E. (2018). The biosocial subject: Sensor technology and worldly sensibility. Discourse: Studies in the Cultural Politics of Education, 39 (2), 292-308.

periphery of the human body, but it is as central to the activity of rumination, deliberation and comprehension as the brain. The challenge is how to engage with this EDA data without, on the one hand, simply acquiescing to the claim that biodata provides a factual foundation for learning theories, and on the other hand, repeating the doxa of social constructivism and simply dismissing such data.

The EDA is a testimony to the force of periphery activity, showing how the sympathetic nervous system is involved in intense biological and personal agency. Wilson (2015) shows how this peripheral nervous system actually dominates the central nervous system in the transmission and distribution of crucial biochemical compounds, such as adrenaline and serotonin. She argues that we must no longer treat 'the biological periphery as psychologically inert', nor treat biology itself as inflexible and an obstacle to politics (p. 16). Investing in the speculative potential of matter, she uses recent work in physiology to argue that 'biological substance' is as much a 'phantasmatic substance' as it is mechanistic (p. 41). She argues that the so-called biological bedrock of the body is robust with both physical and phantastic capacities, a claim that I unpack somewhat differently below, using Protevi's (2013) interpretation of the virtual. The implications for learning theory are risky, as Wilson (2015) calls for the existence of 'organic thought' and the 'biological unconscious', concepts which have an awkward psychoanalytic history. But these are also concepts that help us problematize the conventional coding of such data in terms of cognitive achievement, or as evidence of an all controlling central nervous system, directing our attention instead to the dispersed nature of affect and thought.

The skin sensors are one way to study this dispersed or distributed phantastic capacity. Indeed the skin occupies the quivering periphery of the 'bounded individual' that we take to be the mark of the organ/ism. The EDA skin data is thus perfect for showing how the bounded individual is always being broken down, disassembled, remade, intensified, and charged. Rather than treat synapse and society as disjunctive and antagonistic, one can use the EDA data as a way of tracking the blended world of the peripheral nervous system. At the juncture of the skin, are mixtures of synapse, cilia, sweat, mind, and society, all percolating. Such a reading of the data might be 'biological but nonlocalized; chemical but nondeterministic; interior yet worldly' (Wilson, 2015, p. 106).

I suggest that these chemical and electrical actions are a means of modulating worldly sensibility, of ruminating differently with the world, and making the organic periphery tremble. The EDA data points to our biochemical relationality, our bioaffective dispersal. This new empiricism binds multi-scalar subjects (human and non-human) together in reconfigured modes of existence, transforming human experience from an agent-centered perceptual modality to an unequally distributed 'worldly sensibility' (Hansen, 2015). We need to develop ways of studying the expanded sensory contact that characterizes this new way of life. In this spirit, one might turn to the experiments of Nold (2009) who used EDA technology to remap the affective shape of cities all over the world, creating 3-D maps that combined conventional city maps with the graphical peaks and troughs of the EDA data record, produced by volunteers who walked the city wearing sensors.

My hope is to trigger new experiments in education in which EDA data might be conceived differently, not only in terms of biomarkers of personalized affect, but as evidence of a worldly sensibility that disperses the bounded organism. This also involves 
de Freitas, E. (2018). The biosocial subject: Sensor technology and worldly sensibility. Discourse: Studies in the Cultural Politics of Education, 39 (2), 292-308.

rethinking the nature of digital biotechnologies, not as 'affordances' or 'prosthetic' extensions, but more in terms of the technicity of matter. Thus my approach considers technologies as somewhat indifferent to human interest and achievement, participating in the environment firstly (Galloway \& Thacker, 2007; Gane, 2005; Ruppert et al., 2013). In other words, technology is not only a human invention, but part of a worldly process of ongoing transformation. In the context of biotechnology and biodata, I follow Stevens (2013), who suggests that such data 'bring the material and the virtual into new relationships' (p. 8). The virtual and the actual are continuously folded and refolded through a worldly technicity that is not only of our own making.

\section{Virtuality, intensity and the futurity of matter}

Electro-dermal activity points to the different speeds of becoming, and the articulation of bodies as relations or ratios of speed and rest. EDA data from E4 bracelets is purely differential, insofar as it marks a gradient or rate of change, rather than a definitive quantity that correlates with a particular level of affect (this is why there are always at least two interpretations, as discussed above). Measures of electro-dermal data track changes in electrical skin conductance. These changes are linked to the skin's production of sweat, which is itself linked to the sympathetic nervous system, often said to reflect changes in arousal. Researchers distinguish between 'phasic' data with lots of peaks that seem to mark arousal, and 'tonic' data that record gradual changes in engagement (Kim et al., 2013). The fact that there is always this differential element to the electric body helps us theorize a body that is charged, but never static or still - bodies are related rates of change, each rate itself changing (change of change ...), involving $2^{\text {nd }}, 3^{\text {rd }}$, and nth derivatives. The peripheral nervous system, extending the body into its frayed periphery, carries this charge in nonstop differentiated flows. It's as if individuation of a body is a massive related rates problem. Attending to the electro-magnetic field (as that which sustains a body), we can begin to study the provisionality of human bodies, and the microtemporality of boundedness. As Bennett (2010) suggests, individuation of bodies 'proceeds at a speed or a level below the threshold of human discernment' (p. 58).

Biosensors like the Empatica bracelets detect activity below the perceptual threshold of the human. In this vein, the data testifies to worldly sensibility, attending to the collective nature of radical exteriority. These EDA devices help us track the provisional ground of embodiment, but also the distributed and differential nature of individuation. In other words, rather than demonize the technology as an extraction device that fails to capture lived experience, we need to find better ways to think about these new kinds of digital plug-ins, different ways of understanding the significance of the EDA data. This involves theorizing the wristbands as a means of plugging into an environmental sensibility, a way of connecting with the machinic dimension of generative activity. The term 'machinic' is meant as an alternative to 'motor' as in 'sensory-motor' which has been used in various phenomenologies that continue to position the brain as the administrator of participation. As Deleuze and Guattari (1987) showed, the machinic better captures the acentred nature of our technicity.

But the machinic is not without vitalism. The concept of the virtual is pivotal in clarifying an approach to biosocial data that is not reductive scientism, nor mystical 
de Freitas, E. (2018). The biosocial subject: Sensor technology and worldly sensibility. Discourse: Studies in the Cultural Politics of Education, 39 (2), 292-308.

occultism, but is rather based on an alternative way of understanding the material force of the body. Following Protevi's (2013) lead, I argue here that Deleuzian notions of the virtual and of intensive individuation can be used to analyze micro-sensory data. Deleuze elaborates a distinction between the actual and the virtual, as part of his attempt to build a pluralist ontology. By thinking through the role of the virtual in this data, we can begin to think differently about the capacity of a body, and this I believe is crucial in developing a bioethics for biosocial research. ${ }^{5}$ Deleuze offers a new way of thinking about bodily capacity, less as a fully individuated possibility awaiting realization - achieving its teleological goal of actualization - and more as a live wire or differentiated field of charge. A body's capacity is precisely this terrifying potentiality, this contraction and expansion of forces, this ongoing unexpected worlding. Perception is not the organized synthesis of this sensory surround, but involves another differentiation of already differentiated flows. Protevi (2013) argues that the 'virtual web' of 'linked rates of change' of neural and other material processes is what characterizes this sensory confound. Crucial to this work is the fact that the relationship between the virtual and the actual is not one of resemblance, so as to avoid any suggestion of idealism. The graph of the EDA data is, however, a rendering of micro-sensory bodily activity, and indeed 'represents' bodily activity in terms of a differential or potential. As Protevi suggests, however, there is no relation of resemblance between the virtual field and individuated acts of software processing, but one of different/ciation:

Thus an individuated perception does not resemble the distributed and differential brain-bodyworld system, when that is conceived at the level of a virtual web of linked rates of change of neural, somatic, and environmental processes (p. 138. My italics)

Breaking the rule of resemblance is crucial for reclaiming the electro-dermal 'data' as environmental or ecological rather than only representational of a particular body's properties. But even if we manage to eliminate simplistic notions of resemblance (between sensation and sign), we are still faced with the usual assumption that this microsensory activity determines or causes the more macro bodily activity. This notion of 'determination' is at the heart of the dilemma concerning our use of biosocial data, haunting all attempts to bring the biological and the social sciences together. Protevi (2013) seems optimistic, arguing that Deleuze's work resonates with many ideas from the 4EA movement in embodied cognition, drawing primarily from phenomenology and ecological dynamic systems, where 4EA designates embodied, embedded, enacted, extended, affective. ${ }^{6}$ But many of these theories still hold to a notion of the 'biologically prior' that determines all biosocial expression. Deleuze's emphasis on a virtual differential potential that is actualized in the machinic phylum undermines this kind of determination, and proposes a different process of determination. For Deleuze (1994), determination is a robust process of differenc/tiation, a term he derives from three key ideas in mathematics (see de Freitas, 2016c, for details). These three key aspects of Deleuze's concept of determination (the undetermined, reciprocal determination, the potential) are derived from the calculus and are crucial for how Deleuze moves away from Kant's 'conditions' of perception, towards an explanation of how new sensations come into the world. ${ }^{7}$

We can begin to grasp the significance of this theoretical shift by turning now to more general considerations of speed and temporality in biometric research. Consider the 
de Freitas, E. (2018). The biosocial subject: Sensor technology and worldly sensibility. Discourse: Studies in the Cultural Politics of Education, 39 (2), 292-308.

microtemporal gap that is said to separate neuronal events from consciousness - a missing fraction of a second between brain activation and awareness. Neuroscientists like Antonio Damasio (2003) suggest that this delay undermines the agency of consciousness - it seems as though conscious discernment is simply that which performs or ratifies what has already been 'decided' by the brain. For Damasio, this shows how consciousness is an epiphenomenon, or emergent mental state, a belated effect of its material conditions.

This 'fundamental delay' of consciousness in relation to the brain and the body is often cited when researchers work on biodata like that from E4 bracelets. The accelerated speeds of these new biometric devices seem to subvert the slow deliberative time of human consciousness. Instead, Hansen (2015) argues that contemporary digital media of this kind 'afford no direct correlation to human perceptual experience whatsoever' ( $\mathrm{p}$. 247). He claims that data-gathering from computational microsensors 'modulate[s] worldly sensibility directly' without the human subject necessarily recruiting any value from this activity. The humans are on the sidelines - they may indeed be affected, but indirectly because this new kind of digital technicity is, according to Hansen, simply better at plugging into a worldly vibrational sensibility. Humans - with their unwieldy organs - simply are not as good at plugging into that vibrational sensibility.

So rather than chase the simultaneity of sensory solicitation and response, a goal that inevitably serves the 'brutal functionalism' of marketing firms, and rather than celebrate the tiny delay as the site of some phenomenological affirmation of our right to slow science, Hansen suggests we study micro-sensory data for how it plugs into the futurity of matter. Rather than look backwards at the assumed-to-be-complete event of sensation, and our late arrival, look into a futural matter that harbours unscripted potential (the virtual). Rather than confine the causal efficacy of sensation to past conditions, take up and analyze the data for how it plugs directly into a robust and ongoing sensibility, a worlding process. The issue is how to avoid or resist the controlling hand of predictive analytics, while still affirming this futural matter. Given how sensor data is already being used to fuel predictive analytics, it seems urgent that we develop this theoretical and practical approach to rethinking the nature of this futurity.

The claim that the living present already includes the tickling agitation of the future is part of the phenomenological tradition, proposed by Edmund Husserl using the term 'protention'. But Hansen (2015) suggests that protention was largely based on a 'ground' of finite possibilities, assembled into memory banks that were then tapped, perhaps much like many machine learning algorithms today must tap vast amounts of training data before they turn to the act of prediction. For Husserl, the human subject accessed this potentiality in the present moment through ratiocination or heightened consciousness. The future was then a sort of projection or a set of expectations based on mental or conscious reflection on this accumulated past. Instead, Hansen (2015), following Alfred Whitehead's philosophy of nature, argues that the future is felt in the present because the future is literally produced (rather than predicted) through the real potentiality of matter. That potentiality is felt (by humans) as intensity in the present moment. Intensity becomes the key concept for Hansen, as a complex force (from the future) that animates the present moment. Just as for Deleuze the virtual rumbles perception (and calls forth the actual), for Hansen intensity is the 'vibratory character of actuality' and is the feeling by which we sense the future animating the present moment. The intensity of the present moment 'simply is the index of the power of this potentiality' (p. 210). 
de Freitas, E. (2018). The biosocial subject: Sensor technology and worldly sensibility. Discourse: Studies in the Cultural Politics of Education, 39 (2), 292-308.

If there is a vibrant futurity animating matter, then we need to rethink forms of presencing that are not conventionally phenomenological. The 'present moment' is more or less animated or intensified by an undecidable future. This paper follows Hansen (2015) in suggesting that digital media play a unique role in this situation, as 'the scope of the present depends on the degree of precision of technical access' (p. 195). In other words, the degree of that intensity and the specificity of its affect (joy or fear) depends on our access to a worldly technicity that sustains the undecidability of the future. Biosocial studies of 'active' learning could then attend more carefully to how biosensors are imbricated in worlding processes. Rather than channels by which signals are relayed, biosensors are somewhat indifferent to human achievement and bodily capacity (Gane, 2005). I suggest that such a perspective brings forth a new politics more adequate to the ubiquitous computing environments in which we now dwell. Reckoning with this digital data deluge and milieu requires a new form of resistance. Everything hinges on how well we can live with this 'resolutely technical' matter while resisting the ossifying instrumentality that captures and controls it (Hansen, 2015, p. 198).

\section{The biopolitics of precognition}

Biopolitics describes how capital saturates everyday life - health, hygiene, sexuality, learning - in order to control populations and to extract new value from new kinds of labour. Foucault (1976) used the term biopower to describe the eighteenth century 'explosion of numerous and diverse techniques for achieving the subjugations of bodies and the control of populations' (p. 140). Lazzarato (2002) emphasizes how biopower operates within a complex biopolitical terrain in which control and governance operate along with creative acts of becoming. If earlier versions of biopolitics tended to treat the body as a neutral container shaped entirely by political forces, there is now widespread interest in rethinking the power of the body in contemporary biopolitics (Protevi, 2013).

Deleuze and Guattari (1987) offer similar suggestions, offering a way of thinking the political at diverse scales, tracking traits and flows of capital across the molecular and the molar. In their claim that 'every politics is simultaneously a macropolitics and a micropolitics' they shift focus to the molecular and imperceptible level and to what they call 'the micro-fascisms' that operate beneath and beside the human subject (italics in original, p. 213). This molecularization of politics has the potential to radically open up our research to new ways of attending to the biopolitics of life.

Politics on the grand scale can never administer its molar segments without also dealing with the micro injections or infiltrations that work in its favor or present an obstacle to it; indeed, the larger the molar aggregates, the greater the molecularization of the agencies they put into play. (p. 204)

These micro-injections and infiltrations break through the skin and reorganize the bounded body according to new forces and new desires. The human body becomes a recombinant subject, engaged in distributed decision-making and network forms of becoming. The individual is divided, repeatedly, replaced by disparate trajectories of 'dividuals' - a term that Deleuze and Guattari use to describe the traits that break free from the bounded human body, circulating as part of a biosocial economy. Global capital links the mobile dividuals in a vast network that is highly flexible and transindividual. 
de Freitas, E. (2018). The biosocial subject: Sensor technology and worldly sensibility. Discourse: Studies in the Cultural Politics of Education, 39 (2), 292-308.

Thus the individuated human body, upon which theories of labour and capital were built, is disassembled through Deleuze and Guattari's concept of dividuation and becoming imperceptible. This approach underscores the way in which capitalism extracts value at all scales and speeds, whether it be from human qualities (race, gender, sexual orientation, etc.) or from the labour of non-human electrical charges as they flow across intra-active currents.

We are all too familiar with the threat of those who capitalize on this kind of 'precognitive' biodata. Today's data industries use predictive analytics to target the 'operational present' of molecular/neuronal labour as a means of controlling the future (de Freitas \& Sinclair, 2016). Surely all this granular sensing will lead to nothing else but more control. As Satel \& Lilienfeld (2013) argue, it may be that we need to reject this kind of research because it cannot but undermine our commitment to civic, legal, and ethical notions of freedom. Indeed, is it not the case that biosocial research simply deprives us of our ability to shape how are sensibility becomes our experience?

Tentatively, my answer is no. Here are two reasons for not simply resting with suspicion: (1) EDA data is not simply the recording and storing of human bodily experience, but is also a direct engagement or encounter with an electric worldly 'sensibility'. As argued above, this direct engagement is better studied by attending to the intensity and disparate speeds and dynamics of both individuation and collective coordinated movement; (2) the problem is not so much the technical accessing of biodata but the fact that such data is stolen to serve the control state (Deleuze, 1992). EDA data is here, and we need to deal with it. With these two points in mind, we must not turn our backs on the technology permitting such data capture, but remain vigilant about studying the ways that this technology plugs into a more expansive sensibility.

My approach considers sensibility outside the human-centric notion of perception, as there is no subjective unity capable of hosting such sense-making. If perception is part of learning, it is because the differenc/tiated virtual web of linked speeds is twisted and contracted at particular junctures or events. What is at stake here, then, in EDA research, is a need to think beyond perception studies. Accordingly, Hansen (2015) treats these biosensors as 'media' and defines media as that which 'operate as instruments that mediate sensibility for experiential achievement' (p. 231). We may still need to consider this in terms of some more broadly conceived achievement; perhaps even an achievement that is indifferent to human embodiment, and might be better studied through some other 'climatology' yet to be formulated, tracking the circulation of affect across a charged field (Galloway \& Thacker, 2007, p. 157). The aim is to develop a theoretical framework that avoids the two dangerous poles of posturing scientism and mystical obscurantism. In other words, how might we avoid referencing this biodata as the singular cause of individuated ability, while also avoiding the mystical assignment of occult forces at work in matter? If the human subject is a kind of after-image of subpersonal material processes, what is the best way to 'make sense' of the virtual or intensive nature of these electrical charges as they flit across the wet surfaces of our bodies? If reductive scientisms turn to biosensors like E4 to control the future, what kinds of experiments might we design to show how this intensity belongs to the learning environment? What kind of software analytics will help us analyze EDA data as ecological? And what happens to the notion of 'lived experience' as the focus of most if not all research on learning? Lived experience becomes unrecognizable in a world of microtemporal biometric data that circulates and is 
de Freitas, E. (2018). The biosocial subject: Sensor technology and worldly sensibility. Discourse: Studies in the Cultural Politics of Education, 39 (2), 292-308.

absorbed at rates well below and above the bandwidth of human consciousness. The crucial thing here is that technology is no longer a surrogate for a human faculty or capacity, but instead operates directly on the sensibility of the 'total' environment which precedes and underlies our own corporeal phenomenal experience. The microsensors actually help us study this different/ciated virtual web of linked speeds. Thus the EDA data can actually be seen as exposing the radical exteriority of experience. The challenge is to take up this data, without making it the biomarker of some essential interiority possessed only or even mostly by the individual, so as to better attend to the transindividual collective.

\section{Concluding remarks}

Quantification of life at scales below and above the human suggests a strange new world of immersive measure (Hayles, 2017; Manovich, 2002; Ruppert et al., 2013). These developments in micro-sensory digital technology support post-phenomenological studies of embodied learning, and demand new analytic frames that better integrate the qualitative with the quantitative (de Freitas, 2017). Reclaiming the quantitative dimension of life is perhaps our best way into the radical rethinking of subjectivity called forth by the digital deluge. Hansen (2015) suggests that 'subjectivity' inheres within everything, but that 'the massive proliferation of computing in our world' demands that we reckon with how subjectivity inheres in quantitative data (p. 12). One wonders whether such an approach resonates with that of Vicky Kirby (2011) and Karen Barad (2017) insofar as these two scholars suggest that the world is investigating itself mathematically, and that 'animate and (so-called) inanimate creatures do not merely embody mathematical theories; they do mathematics' (Barad, 2017, pp. 1-2). Even the most seemingly inert, objectified and datafied event or body is part of a new circuit of sensory links within a qual-quant milieu (de Freitas, Dixon-Ramon \& Lather, 2016). In turning to the subjective and social nature of the quantitative, I am not positing a 'real' that lurks behind the quantitative, or an authentic subject that fails to be captured by measure. Instead I have argued that sensor data is implicated in (rather than explicating of) a direct (but unequal) sharing of worldly sensibility. This approach aims to rethink the human as an inseparable ingredient of a larger environmental sensory milieu.

As biosocial research maps a new biopolitical terrain, I see a need to shift the focus from theories of agent-centred perceptual capacities to theories of worldly sensibility and 'environmentality'. Through biosocial research, and related policy, the student's body is being reconfigured and reassembled, and the conventional understanding of how a learner learns is changing. Sensor data is precisely the kind of data that all too easily joins the accelerated flows of traits and tensors, as the human organism breaks apart. For this reason, we need to find new ways of studying the material ecology of classrooms and learning environments, refusing to package sensation in terms of biomarkers of dis/ability. New kinds of questions need to be posed by researchers, questions that can help us build more complex models of the charged environment, to avoid being trapped in overly simplistic models of stimulus-response, and to enhance our appreciation for the worldly sensibility that is at stake.

In this article I offer a different way of analyzing EDA data, refusing the various scientisms and psychologisms that serve to centre subjects with privileged access to their 
de Freitas, E. (2018). The biosocial subject: Sensor technology and worldly sensibility. Discourse: Studies in the Cultural Politics of Education, 39 (2), 292-308.

biosocial experience. But I realize that the call to decentre the human so as to better encounter a lively world that is indifferent and yet complementary to humans is, well, slightly duplicitous and politically fraught. This is a precarious project - I aim to encounter the more-than-human so as to imagine a future for the human. Johnston (2013) claims that these theoretical moves are driven by an ecological politics that has yet to really displace the human, and that emphasis on 'relational ontologies' is a back-door way of re-inserting the human in the world. Harman (2016) similarly claims that relational ontologies like that of Deleuze and Whitehead are always imagining a relational material world that is saturated with a human image of the virtual.

Hansen (2015), however, sees his project as ultimately and unapologetically serving humans. In fact he critiques contemporary theorists working on the posthuman (including the speculative realist Graham Harman and the new materialist Jane Bennett) for arguing a position that is anti-human in their work. Instead, he sees his work as an attempt to 'grasp the place of the human within today's media networks' (Hansen, 2015, p. 2). Looking for a 'properly elemental conception of the human', we must, suggests Hansen:

... adopt a radically environmental perspective encompassing human activity as one element among others: such a perspective views human agency just as it does any other type of agency, namely, as internally differentiated, dispersed across various scales and operational divisions, and implicated in and immanent to a total, multi-scalar cosmological situation. (p. 2)

This is not an impersonal objectifying of the world, but a reconceptualizing of subjectivity as 'intrinsic to the sensory affordances that inhere in today's networks and media environments' (Hansen, 2015, p. 3). Sensory digital devices like neuro-imaging and electro-dermal bracelets and other 'smart' sensors produce surplus data that is then tapped by researchers and potentially folded into capitalist circuits of exploitation. For this reason, if no other, we must ask: How can more than human research practices serve an expanded notion of justice that might counter the forces of a control society? Rethinking the nature of presence and mediation is crucial as we explore possible answers to that question.

The idea, then, is that human experience is undergoing change caused by our entanglement with contemporary media environments, and that the directionality of this transformation inverts the long-standing privilege held by humans as the well-nigh unique addressee of media. (Hansen, 2015, p. 6)

This article is a call to researchers to pursue counter-deployments of these new media interventions, to reclaim the sensory data stolen from skin, neuron, eye, and electrical impulse, and build a new kind of empiricism that seeks the 'production of intensity' while also ensuring an ethical future for laboring human bodies (Hansen, 2015, p. 66). The concept of intensity plays a pivotal role here, because intensity, rather than perception, better expresses the more-than-human forces operating alongside the human: 'intensity is precisely what is at stake experientially in twenty-first-century media's direct mediation of worldly sensibility' (p. 103).

\section{Acknowledgments}


de Freitas, E. (2018). The biosocial subject: Sensor technology and worldly sensibility. Discourse: Studies in the Cultural Politics of Education, 39 (2), 292-308.

I would like to acknowledge support from the Biosocial Laboratory at Manchester Metropolitan University, and contributions of ideas from colleagues Maggie Maclure and David Rousell.

\section{Notes}

${ }^{1}$ Economic \& Social Research Council (2014) ESRC framework to enable biosocial research. $\mathrm{http} / / / \mathrm{www} . e s r c . a c . u k /$ files/research/framework-to-enable-biosocial-research-pdf/

2 As Nafus (2016) points out, a broad definition of 'biosensor' helps open up the conversation around subjectivity and self.

${ }^{3}$ Epigenetic research has inherited cybernetic notions of receptor and relay, so that the environment now 'signals' and is transduced through bodies (Landeker, 2016).

${ }^{4}$ The lead MIT researcher at the lab, Rosalind Picard, founder of the company Affectiva, is interested in how EDA might help Autists, and people suffering from seizures, anticipate and thereby avoid traumatic incidents. For other examples of research in this area, see Choi, Ahmed, \& Gutierrez-Osuna (2012), Hernandez et al. (2014), and Sano \& Picard (2013).

${ }^{5}$ Hansen (2015) - whose work we discuss in more detail below - critiques Deleuze and the concept of the virtual, and emphasizes intensity instead. Indeed, Hansen is keen to differentiate himself from many other theorists. Despite these claims, our reading of Deleuze - his work on both virtuality and intensity shows the relevance of his work.

${ }^{6}$ Protevi cites Anthony Chemero (2009), Alva Noe (2004), and Michael Wheeler (2005). He then adds and complicates this work in embodied cognition by introducing ideas from Gilles Deleuze (in particular the concept of the virtual).

${ }^{7}$ Although not adequate room here to develop this idea, there are important ways in which the concept of the virtual offers a twist to conventional theories of emergence. There is also increasingly more work on quantum cognition and quantum sociology, offering alternative ways of conceiving of 'determination' in contrast to the concept of 'emergence' as articulated in dynamic systems theory (see, for instance, Alexander Wendt (2015).

\section{References}

Banaee, H., Ahmed, M. U., \& Loutfi, A. (2013). Data mining for wearable sensors in health monitoring systems: A review of recent trends and challenges. Sensors, 13(12), 17472-17500.

Barad, K. (2017). When two hands touch, how close are they? On touching the inhuman that therefore I am. In K. Stakemeier, \& S. Witzgall (Eds.), Power of material/politics of materiality (pp. 153-165). Zurich, SW: Diaphanes. Retrieved from http://www.diaphanes.de/titel/ontouching-the-inhumanthattherefore-i-am-v1-1-3075 (accessed on August 29 2017). Originally published in Differences: A Journal of Feminist Cultural Studies, 23(3), 206-223.

Bennett, J. (2010). Vibrant matter. Durham, NC: Duke University Press.

Bertucci, P., \& Pancaldi, G. (2001). Electric bodies: Episodes in the history of medical electricity. Bologna Studies of History of Science, 9. University of Bologna.

Chemero, A. (2009). Radical embodied cognitive science. Cambridge, MA: MIT Press. 
de Freitas, E. (2018). The biosocial subject: Sensor technology and worldly sensibility. Discourse: Studies in the Cultural Politics of Education, 39 (2), 292-308.

Choi, J., Ahmed, B., \& Gutierrez-Osuna, R. (2012). Development and evaluation of an ambulatory stress monitor based on wearable sensors. Information Technology in Biomedicine, IEEE Transactions On, 16(2), 279-286.

Coenen, T., Coorevits, L., \& Lievens, B. (2015). The wearable Living Lab: How wearables could support Living Lab projects. Presented at the Open Living Lab Days 2015, Istanbul, Turkey.

Colebrook, C. (2011). Essays on extinction. Open Humanities Press. Creative Commons. Available at: www.openhumanitiespress.org/books/titles/sex-after-life

Colebrook, C. (2014). Socially invaded: The biosocial subject. Environment and Planning: Society and Space, 32, 556-570. Accessed October 30, 2017 at http://journals.sagepub.com/doi/pdf/10.1068/d3203rev

Damasio, A. (2003). Looking for Spinoza: Joy, sorrow and the feeling brain. New York: Harcourt Inc. de Freitas, E. (2016a). Calculating matter and recombinant subjects: The infinitesimal and the fractal fold. Cultural Studies - Critical Methodologies, 16(5), 462-470.

de Freitas, E. (2016b). The new empiricism of the fractal fold: Rethinking monadology in digital times. Cultural Studies - Critical Methodologies, 16(2), 224-234.

de Freitas, E. (2016c). Deleuze, ontology and mathematics. Encyclopedia of Educational Philosophy and Theory. https://link.springer.com/referenceworkentry/10.1007\%2F978-981-287-532-7 374-1

de Freitas, E. (2017). The temporal fabric of research method: Posthuman social science and the digital data deluge. Research in Education. http://journals.sagepub.com/toc/riea/98/1

de Freitas, E., \& Sinclair, N. (2016). The cognitive labour of mathematics dis/ability: Neurocognitive approaches to number sense. International Journal of Education Research, 79, 220-230.

de Freitas, E., Dixon-Román, E., \& Lather, P. (2016). Alternative ontologies of number: Rethinking the quantitative in computational culture. Cultural Studies-Critical Methodologies, 16(4), 1-4.

Deleuze, G. (1992). Postscript on the societies of control. October, 59, 3-7. doi: 10.2307/778828.

Deleuze, G. (1994). Difference and repetition (P. Patton, Trans.). New York, NY: Columbia University Press.

Deleuze, G., \& Guattari, F. (1987). A thousand plateaus: Capitalism and schizophrenia. (Trans. B. Massumi). Minneapolis: University of Minneapolis Press.

Dyson, F. (2007). Our biotech future. New York Review of Books. July Issue. Accessed October 30, 2017. http://www.nybooks.com/articles/2007/07/19/our-biotech-future/

Fitzgerald, D., \& Callard, F. (2015). Social science and neuroscience: Beyond interdisciplinarity. Theory, Culture and Society, 32(1), 3-32.

Foucault, M. (1976). The history of sexuality, Volume 1: An introduction. (Trans. R. Hurley). New York: Vintage Books.

Frost, S. (2016). Biocultural creatures: Toward a new theory of the human. Durham, NC: Duke University Press.

Galloway, A., \& Thacker, E. (2007). The exploit: A theory of networks. Minneapolis: University of Minnesota Press.

Gane, N. (2005). The radical post-humanism of Friedrich Kittler: The primacy of technology. Theory, culture and Society, 22(3), 25-41.

Gillborn, D. (2016) Softly, softly: Genetics, intelligence and the hidden racism of the new geneism. Journal of Education Policy, 31(4), 365-388. 
de Freitas, E. (2018). The biosocial subject: Sensor technology and worldly sensibility. Discourse: Studies in the Cultural Politics of Education, 39 (2), 292-308.

Goodman, A. (2013), Bringing culture into human biology and biology back into anthropology. American Anthropologist, 115(3), 359-373.

Gravlee, C. (2009), How race becomes biology: Embodiment of social inequality. American Journal of Physical Anthropology, 139(1), 47-57.

Hansen, M. (2015). Feed-forward: On the future of twenty-first-century media. Chicago: University of Chicago Press.

Harman, G. (2016). Agential and speculative realism: Remarks on Barad's ontology. Rhizomes: Cultural Studies in Emerging Knowledge, 30. doi: 10.20415/rhiz/030.e10.

Hayles, N. K. (2017). Unthought: The power of the cognitive nonconscious. Chicago: University of Chicago Press.

Hernandez, J., Riobo, I., Rozga, A., Abowd, G. D., \& Picard, R. W. (2014). Using electrodermal activity to recognize ease of engagement in children during social interactions. In Proceedings of the 2014 ACM International Joint Conference on Pervasive and Ubiquitous Computing (pp. 307-317).

Ingold, T., \& Palsson, G. (Eds.). (2013). Biosocial becomings: Integrating social and biological anthropology. Cambridge: Cambridge University Press.

Johnston, A. (2013). Prolegomena to any future materialism: The outcome of contemporary French philosophy. Evanston, IL: Northwestern University Press.

Kim, J., Snodgrass, M., Pietrowicz, M. Karahalios, K., Halle, J. (2013). BEDA: Visual analytics for behavioural and physiological data. Accessed Nov. 2017. Available at social.cs.uiuc.edu/papers/pdfs/BEDA_camera_ready_version_VAHC_kim.pdf

Kirby, V. (2011). Quantum anthropology. Durham, NC: Duke University Press.

Kohn, E. (2013). How forests think: Towards an anthropology beyond the human. Berkeley, CA: University of California Press.

Landeker, H. (2016). The social as signal. The Sociological Review Monographs, 64(1), 79-99.

Lazzarato, M. (2002). From biopower to biopolitics. Pli: The Warwick Journal of Philosophy, 13, 112-125.

Lupton, D. (2014). Self-tracking cultures: Towards a sociology of personal informatics. In Proceedings of the 26th Australian Computer-Human Interaction Conference on Designing Futures: The Future of Design, 77-86. December 2-5. University of Technology, Sydney, Australia. New York: ACM.

Manovich, L. (2002). The language of new media. Cambridge, MA: MIT Press.

Meloni, M. (2016). Political biology: Science and social value in human heredity from eugenics to epigenetics. Basingstoke: Palgrave Macmillan.

Meloni, M., Williams, S., \& Martin, P. (2016). The biosocial: Sociological themes and issues. The Sociological Review Monographs, 64(1), 7-25.

Nafus, D. (2016). Quantified: Biosensing technologies in everyday life. Cambridge: MIT Press.

Noe, A. (2004). Action in perception. Cambridge, MA: MIT Press.

Nold, C. (2009). Emotional cartography: Technologies of the self. Creative Commons: http://www.emotionalcartography.net/

Papoulias, C., \& Callard, F. (2010). Biology's gift: Interrogating the turn to affect. Body \& Society, 16(1), $29-56$.

Piccolini, M., \& Bresadola, M. (2013). Shocking frogs: Galvani, Volta and the electric origins of neuroscience. Oxford: Oxford University Press.

Platoni, K. (2015). We have the technology: How biohackers, foodies, physicians \& scientists are transforming human perception, one sense at a time. New York: Basic Books. 
de Freitas, E. (2018). The biosocial subject: Sensor technology and worldly sensibility.

Discourse: Studies in the Cultural Politics of Education, 39 (2), 292-308.

Protevi, J. (2013). Life, war, earth: Deleuze and the sciences. University of Minnesota Press: Minneapolis, $\mathrm{MN}$.

Rose, N. (2013). The human sciences in a biological age. Theory, Culture \& Society, 30(1), 3-34.

Ruppert, E., Law, J., \& Savage, M. (2013). Reassembling social science methods: The challenge of digital devices. Theory, Culture and Society, 30(4), 22-46.

Sano, A., \& Picard, R. W. (2013). Stress recognition using wearable sensors and mobile phones. In Affective computing and intelligent interaction (ACII), 2013. Humaine Association Conference (pp. 671-676). IEEE.

Satel, S., \& Lilienfeld, S. (2013). Brainwashed: The seductive appeal of mindless neuroscience. New York: Basic Books.

Stevens, H. (2013). Life out of sequence: A data-driven history of bioinformatics. Chicago: University of Chicago Press.

Van Ijzendoorn, M. H., Bakermans-Kranenburg, M. J., \& Ebstein, R. P. (2011). Methylation matters in child development: Toward developmental behavioral epigenetics. Child Development Perspectives, 5(4), 305-310.

Wendt, A. (2015). Quantum mind and social science: Unifying physical and social ontology. London, UK: Cambridge University Press.

Wheeler, M. (2005). Reconstructing the cognitive mind: The next step. Cambridge, MA: MIT Press.

Wilson, E. (2015). Gut feminism. Durham, NC: Duke University Press.

Williamson, B. (2016). Digital education governance: Data visualization, predictive analytics, and 'realtime' policy instruments. Journal of Education Policy, 31(2), 123-141.

Youdell, D. (2016). Bioscience and the sociology of education: The case for biosocial education. British Journal of Sociology of Education, http://dx.doi.org/10.1080/01425692.2016.1272406 